\title{
Posturas docentes em cursos de formação de professores em serviço: é possível transformá-las no curto prazo?
}

\author{
CLAUDIA DAVIS \\ FCC e PUC-SP \\ YARA LÚCIA ESPOSITO \\ FCC \\ MARINA MUNIZ ROSSA NUNES \\ FCC \\ CESAR AUGUSTO AMARAL NUNES \\ OORT e USP
}

\section{RESUMO}

O presente artigo tem por objetivo analisar e discutir o processo de mudanças em posturas docentes em alunos-professores que participaram de um programa de formação pedagógica superior durante o exercício do magistério. O estudo envolveu 1131 alunos-professores (inclusive de educação infantil) que participaram do PEC-Município $2^{\text {a }}$ edição, sempre que eles forneceram todas as informaçôes necessárias às análises aqui empreendidas. Dois instrumentos foram empregados para coletar os dados: simulaçóes que envolviam três posturas docentes e um questionário que buscava caracterizar os alunos-participantes, por meio de uma série de questóes fechadas. A coleta deu-se em duas etapas: no início do curso (junho de 2006) e ao seu final (dezembro de 2007). Os dados de entrada e saída foram comparados, mostrando que $75 \%$ dos alunos-professores obtiveram avanços significativos em relação aos aspectos estudados. Os principais fatores que interferiram nos resultados foram o ponto de partida (grupo ou "clusters" formados no pré-teste), a atuação profissional e o pólo (universidade) 
a que os participantes estavam vinculados. Mudanças de postura ocorreram sobretudo no grupo que se mostrou inicialmente mais despreparado e com perfis docentes bem distantes dos pretendidos pelo PEC-Município 2a edição. Essa alteração substancial de cenário deveuse, em parte, ao patamar de entrada desses participantes, que enfrentavam em suas rotinas de trabalho condições efetivamente menos favoráveis do que os demais, mostrando a importância da eqüidade nos programas de capacitação, notadamente quando se esperam mudanças não apenas de ordem cognitiva, mas também na forma de sentir e agir.

Palavras-chave: posturas docentes, capacitação em serviço, eqüidade, PEC-Município 2a edição.

\section{RESUMEN}

El presente artículo tiene como objetivo analizar y discutir el proceso de cambios en las actitudes docentes de alumnos-profesores que participaron de un programa de formación pedagógica superior durante el ejercicio del magisterio. El estudio comprendió 1131 alumnos-profesores (inclusive de educación infantil) que participaron del PEC-Municipio 2a edición, siempre que ellos suministraran todas las informaciones necesarias para los análisis emprendidos. Se emplearon dos instrumentos para la recolección de datos: simulaciones que incluían tres posturas docentes y un cuestionario que buscaba caracterizar a los alumnos-participantes, por medio de una serie de preguntas cerradas. La recolección se dio en dos etapas: al inicio del curso (junio de 2006) y al final (diciembre de 2007). Se compararon los datos iniciales y finales, mostrando que $75 \%$ de los alumnos-profesores lograron significativos avances en relación a los aspectos estudiados. Los principales factores que interfirieron en los resultados observados fueron el punto de partida (grupo o "clusters" formado en el pre test), la actuación profesional y el polo (universidad) al que estaban vinculados los participantes. Los cambios de actitud ocurrieron sobretodo en el grupo que inicialmente se mostró menos preparado y con perfiles docentes bien distantes de los pretendidos por el PEC-Municipio 2a edición. Esa alteración substancial del escenario se debió, en parte, al punto de partida de esos participantes, que enfrentaban en sus rutinas de trabajo condiciones efectivamente menos favorables que las de los demás, mostrando la importancia de la equidad en los programas de capacitación, especialmente cuando se esperan cambios no sólo de orden cognitivo, sino también en la forma de sentir y actuar.

Palabras clave: posturas docentes, capacitación en servicio, equidad, PEC-Municipio 2a edición.

\section{ABSTRACT}

This article will analyze and discuss the process of change in teachers' attitudes by teacherstudents in a higher education course during their period teaching. The study involved 1,131 teacher-students (including child education teachers) who took part in the $2^{\text {nd }}$ edition of the PEC-Municipality (PEC-Municipio), as long as they provided all the information necessary for the analyses carried out in this paper. Two tools were used to collect the data: simulations which involved three teaching attitudes and a questionnaire to characterize the studentparticipants by means of a series of closed questions. The data was collected in two stages: 
at the beginning of the course (June 2006) and at the end (December 2007). The initial and final data were compared and showed that $75 \%$ of the teacher-students achieved significant progress concerning the aspects under study. The main factors that interfered in the results were the starting point (group or clusters in the pre-test), their professional experience and the institution (university) to which they were linked. Changes in attitude occurred mainly in the group that was less prepared at the start and whose profile was at quite a distance from what was aimed at by the PEC-Municipality $2^{\text {nd }}$ edition. This substantial change was partly due to the initial level of these participants, who faced much less favorable conditions in their routine work than the remainder of the group, demonstrating how important equality is for continuing education programs, mainly when not only cognitive changes are expected, but also changes in their ways of feeling and acting.

Keywords: teachers' attitudes, in-service continuing education, equality, PEC-Municipality $2^{\text {nd }}$ edition. 



\section{INTRODUÇÃO}

O presente artigo tem por objetivo discutir o processo de mudanças em posturas docentes em professores que participaram de um programa de formação pedagógica superior durante o exercício do magistério.

Ao final dos anos 90, os professores vinculados à rede estadual paulista de ensino, que contavam apenas com habilitação em nível médio, tiveram à sua disposição, oferecido e patrocinado pelo governo do Estado de Sáo Paulo, um programa de formação superior que era realizado durante o exercício do magistério. Surgia o Programa de Educação Continuada em Formação Universitária, denominado PECFormação Universitária, resultado de parceria entre o Estado de São Paulo e três renomadas universidades paulistas. Encerrada a etapa de formaçáo dos professores na rede estadual, o Programa foi oferecido, com alguns ajustes, a municípios que tinham interesse em propiciar curso superior a seus quadros. Fizeram parte dessa fase apenas duas das universidades que originalmente desenvolveram o Programa: começava o PEC-Município, levado a termo em duas ediçóes ${ }^{1}$.

Um dos aspectos investigados nesse Programa dizia respeito às posturas docentes. Entendeu-se que "posturas são tendências ou disposições adquiridas e relativamente duradouras, que levam as pessoas a avaliar, de um determinado modo, um objeto, indivíduo, acontecimento ou situação e a atuar de acordo com tal avaliação" (Coll et al., 1992). É característica das posturas, portanto, serem constituídas na e pela ação. Por envolver múltiplos aspectos, mudanças de posturas são difíceis de ser consolidadas e raramente ocorrem no curto prazo. Náo obstante, elas náo são perenes e podem, diante de novas experiências, sofrer alteraçóes significativas.

Alterar posturas, para que elas se encaminhem na direção de modos socialmente valorizados de agir, pensar e sentir exige: modificaçôes cognitivas, por meio da oferta de novas informaçóes que tenham um maior e melhor potencial explicativo das açóes; estabelecimento de relaçóes afetivas e emocionais fortes nas circunstâncias em que a mudança ocorre; capacidade de generalizaçáo da postura adotada, por abarcar um leque grande de experiências². (Davis et al., 2007)

O estudo acerca de posturas docentes é importante porque muitas vezes os projetos de capacitaçáo docente enfatizam os aspectos cognitivos, o que permite aos

\footnotetext{
${ }^{1}$ As principais características do Programa encontram-se descritas em Davis et al., 2007.

${ }^{2}$ Uma discussão mais aprofundada acerca de posturas docentes pode ser também encontrada em Coll et al., 1992.
} 
professores saberem o que deve ser feito em situaçóes de ensino. No entanto, saber não implica modificação na ação. Por motivos variados, em geral atribuídos às muitas faltas que assolam o espaço escolar - de material necessário, de apoio do coordenador pedagógico, da experiência pessoal validar o que foi transmitido, de interesse da família ou dos próprios alunos etc. - o que foi divulgado no curso de capacitação não é posto em prática e, como conseqüência, a docência segue inalterada. De fato, como mencionado acima, a mudança exige mais do que informação: vontade de fazer diferente e de acertar mais com um número maior de alunos, prazer em fazer um trabalho mais bem sucedido, empenho ao enfrentar o novo. Nesse sentido, cognição e emoção são duas faces da mesma moeda: sem ambas, o novo permanece virtual. Os resultados aqui apresentados referem-se às modificaçóes encontradas nas posturas docentes dos alunos-professores vinculados à 2a edição do PEC-Município e suas respectivas tentativas de explicação.

\section{MÉTODO}

\subsection{Objetivos}

Foram duas as metas desse estudo:

2.1.1 verificar quais eram as posturas docentes de alunos que já se encontravam inseridos no magistério, examinando se elas se alteravam como resultado da participação em um curso de formação superior em serviço;

2.1.2 identificar, dentre as características dos professores, aquelas que poderiam influenciar a forma como respondiam ao instrumento em que se avaliavam as posturas docentes e suas transformaçôes.

\subsection{Sujeitos}

Esse estudo envolveu 1131 alunos-professores que participaram do PEC-Município $2^{a}$ edição e que responderam aos instrumentos nas duas etapas da avaliação. A amostra de alunos-professores envolveu, desse modo, cerca de 50\% dos 2133 participantes do referido Programa que, nessa versão, incluiu também profissionais ligados à educação infantil. Todos os participantes eram vinculados à rede municipal de 13 municípios e de cinco regiôes administrativas da Grande São Paulo.

\subsection{Instrumentos de coleta de dados}

Foram empregados dois instrumentos para que se pudesse verificar se as posturas docentes se modificavam - e em qual direção - em função de ter participado do curso. O primeiro deles - simulaçóes de posturas docentes - era constituído por 
duas seqüências de situaçôes-problema próprias do cotidiano escolar, apresentadas na forma de situações animadas a serem respondidas individualmente, por via de computador. Cada tarefa exigia que decisóes fossem tomadas pelos participantes, e as resoluçóes tomadas permitiam identificar se havia afinidade entre os procedimentos selecionados pelos alunos-professores e aqueles propostos pelo Programa em estudo. Três posturas docentes foram investigadas.

O segundo instrumento buscava caracterizar os alunos-participantes, por meio de uma série de questóes fechadas. A coleta de dados deu-se em duas etapas, com os mesmo instrumentos sendo apresentados no início do curso (junho de 2006) e ao seu final (dezembro de 2007). Esse modelo foi adotado por permitir verificar se houve modificaçóes nas referidas posturas e, em caso positivo, em qual direção. Os resultados obtidos no pré e no pós-testes foram comparados.

\section{ANÁLISE E INTERPRETAÇÃO DE DADOS}

Os dados das simulaçóes foram reunidos em três posturas, cada uma delas formada por três perfis (classificados de perfil 1, 2 e 3). O perfil 1 reunia as respostas tidas como insatisfatórias em face do preconizado no PEC (em suas diferentes ediçóes), enquanto o perfil 3 concentrava as mais adequadas e congruentes com os postulados nele adotados. No perfil 2 encontravam-se as respostas entendidas como intermediárias, que mesclavam aspectos satisfatórios e insatisfatórios, situando-se, dessa maneira, entre o perfil 1 e 3 . Duas análises foram feitas, visando a identificar: a) o desempenho dos participantes ao resolver as simulaçóes voltadas para a postura docente; e b) a influência das características dos alunos-professores no desempenho alcançado nas simulaçóes.

\subsection{Descrição das posturas estudadas e classificação dos participantes nos perfis associados a cada postura}

3.1.1 Postura I - Domínio e planejamento de conteúdos básicos das áreas de conhecimento tratadas no Programa

As sete simulaçóes que contribuíram para o estudo da postura I estavam relacionadas às disciplinas de Língua Portuguesa, História, Geografia, Matemática e Ciências e tinham como objetivo principal verificar se os alunos-professores valorizavam: a) o trabalho com diferentes gêneros de discurso, salientando sua estrutura; b) a manipulação de materiais em situações experimentais, bem como a reflexão cientí- 
fica acerca dos dados coletados; c) o uso de tecnologias no ensino, sempre que elas se mostrassem pertinentes; d) o conhecimento prévio, o diálogo e a expressão dos alunos, ao planejar as aulas; e) a forma como deveriam ser trabalhados os conteúdos de História e Geografia. A análise dos resultados indicou diferenças significativas nesse tipo de conduta dos alunos-professores, do início para o final do curso, como pode ser observado no gráfico 1 .

Gráfico 1 - Porcentuais de alunos-professores encontrados nos diferentes perfis da postura I, ao início e ao final do PEC-Município $2^{\text {a }}$ edição

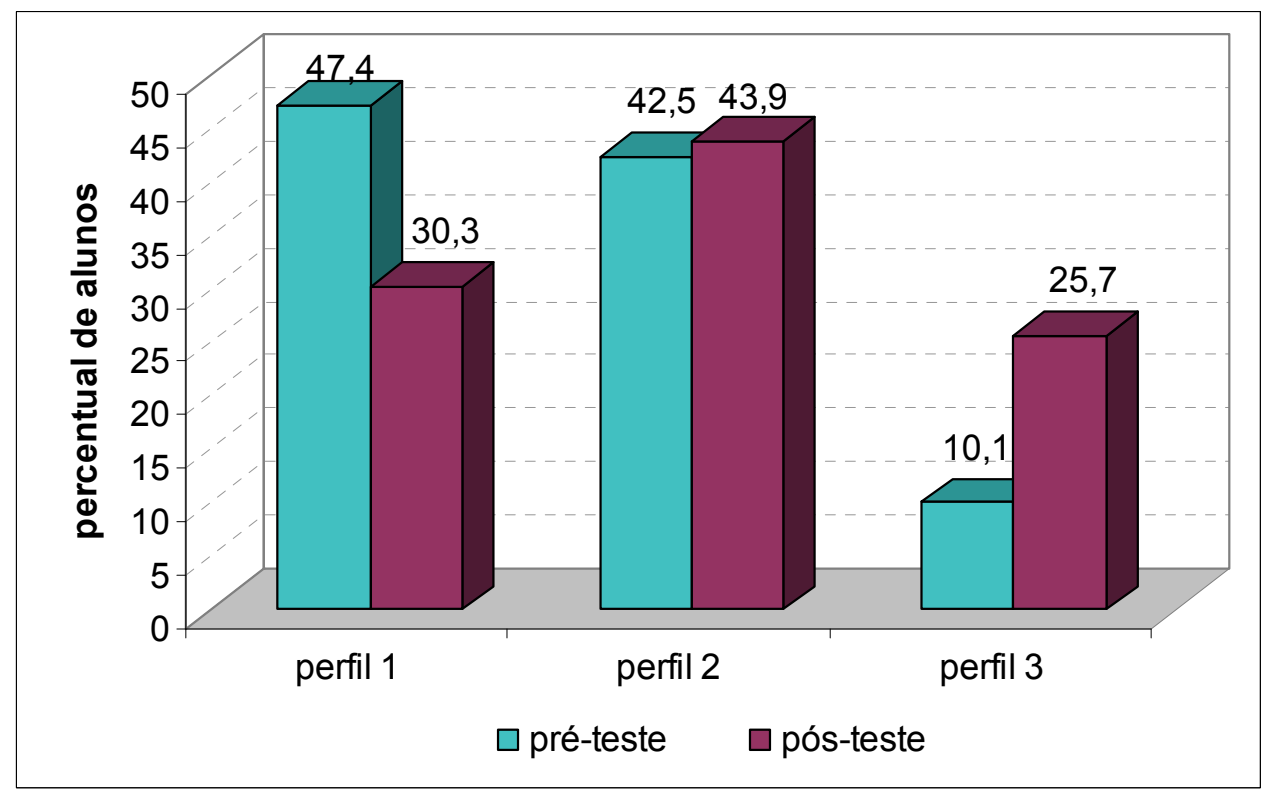

O gráfico 1 mostra que 25,7\% dos alunos-professores responderam às simulaçóes, tomando as decisóes mais adequadas segundo as perspectiva dos objetivos do curso, sendo agrupados no perfil 3. As respostas aí obtidas revelam, em sua maioria, profissionais que consideravam os conhecimentos prévios dos alunos ao planejar e apresentar atividades para o grupo, que selecionavam com pertinência uma seqüência didática e que aproveitavam as situaçóes criadas, para estimular a reflexão do grupo. Aparentavam segurança e domínio nas áreas básicas de conhecimento. $\mathrm{O}$ crescimento do número de professores classificados nesse perfil é ainda mais expressivo quando se considera que no pré-teste apenas $10,1 \%$ dos participantes havia se comportado dessa forma. 
Observou-se, ainda, ligeiro aumento no porcentual de alunos-professores que se enquadraram no perfil 2: de $42,5 \%(\mathrm{n}=481)$ dos participantes no pré-teste passouse para 43,9\% ( $\mathrm{n}=497)$, no pós-teste. Esse grupo reuniu os participantes do curso que consideravam os conhecimentos prévios dos alunos ao planejar e apresentar atividades para o grupo; escolhiam, por vezes, seqüências didáticas motivadoras, sem conseguir justificá-las de maneira consistente e apresentavam certa insegurança ao desenvolver o trabalho nas áreas básicas de conhecimento.

Um resultado interessante, que aponta na direção da eficiência do curso para esse grupo de alunos-professores, pode ser encontrado na análise do comportamento de entrada e de saída relativo ao perfil $\mathbf{1}$, no qual foram encontradas as posturas docentes mais distantes das apregoadas pelo PEC-Município $2^{a}$ edição: profissionais que se atinham a um posicionamento bastante tradicional em suas opçóes de ensino ou que demonstravam freqüente inconsistência no planejamento e no delineamento de atividades para seus alunos. Isso se acentuava quando se viam diante de situaçôes didáticas que envolviam as áreas básicas de conhecimento. Enfatizavam, assim, no trabalho de produção de texto, apenas a aquisição do código da escrita, náo priorizando a estrutura do gênero trabalhado. Ainda que propusessem procedimentos coerentes com suas concepçóes de ensino, desconsideravam a importância do experimento científico. Com freqüência, selecionavam seqüências didáticas aparentemente aleatórias e sem sentido. No início do curso, essa descrição se aplicava à metade do grupo que compunha a amostra final deste estudo: 536 alunos (47,4\%). Ao término do curso, notou-se uma diminuição sensível daqueles que ainda apresentavam condutas classificadas nesse perfil: 343 participantes (30,3\%).

3.1.2 Postura II - Reconhecimento e emprego adequado de recursos e tecnologias disponíveis no processo de ensino-aprendizagem

Os resultados obtidos com a aplicação das simulaçóes elaboradas para a avaliação dos alunos-professores, sobre reconhecimento e emprego adequado de recursos e tecnologias disponíveis no processo de ensino-aprendizagem (postura II), mostraram que há uma alteração representativa do número de sujeitos nos perfis 1,2 e 3 quando confrontados os dados do pré e pós-teste. Na primeira aplicaçáo, dos 1.131 sujeitos que responderam a todos os instrumentos da avaliação, 490 foram classificados no perfil 1, 503 no perfil 2 e 138 no perfil 3. Os resultados do pós-teste indicaram 277 sujeitos $(24,5 \%$ do total) no perfil 1, uma reduçáo de $43,5 \%$ em relaçáo ao pré-teste, no perfil que descreve a postura docente mais distante dos objetivos do Programa. O perfil 1 englobou dois tipos de profissionais: 
a) aqueles que revelaram uma atuação tradicional, na qual se deixava de criar oportunidades para promover a autonomia dos alunos e náo se construía um ambiente de aprendizagem agradável. Esses docentes tendiam, ainda, a estigmatizar os alunos menos experientes e náo se posicionaram claramente a respeito da necessidade de criar vínculos com os estudantes, privilegiando, em sua maioria, práticas pedagógicas que buscavam assegurar, sobretudo, uma maior organização da sala de aula. Além disso, o uso de tecnologias era negligenciado;

b) aqueles que apresentaram atuação "inconsistente" cujas opções realizadas nas situaçóes cotidianas das simulaçôes não apresentam coerência entre si. O gráfico 2 mostra esses resultados em termos porcentuais.

Gráfico 2 - Porcentuais de alunos-professores encontrados nos diferentes perfis da postura II, ao início e ao final do PEC-Município $2^{\text {a }}$ edição

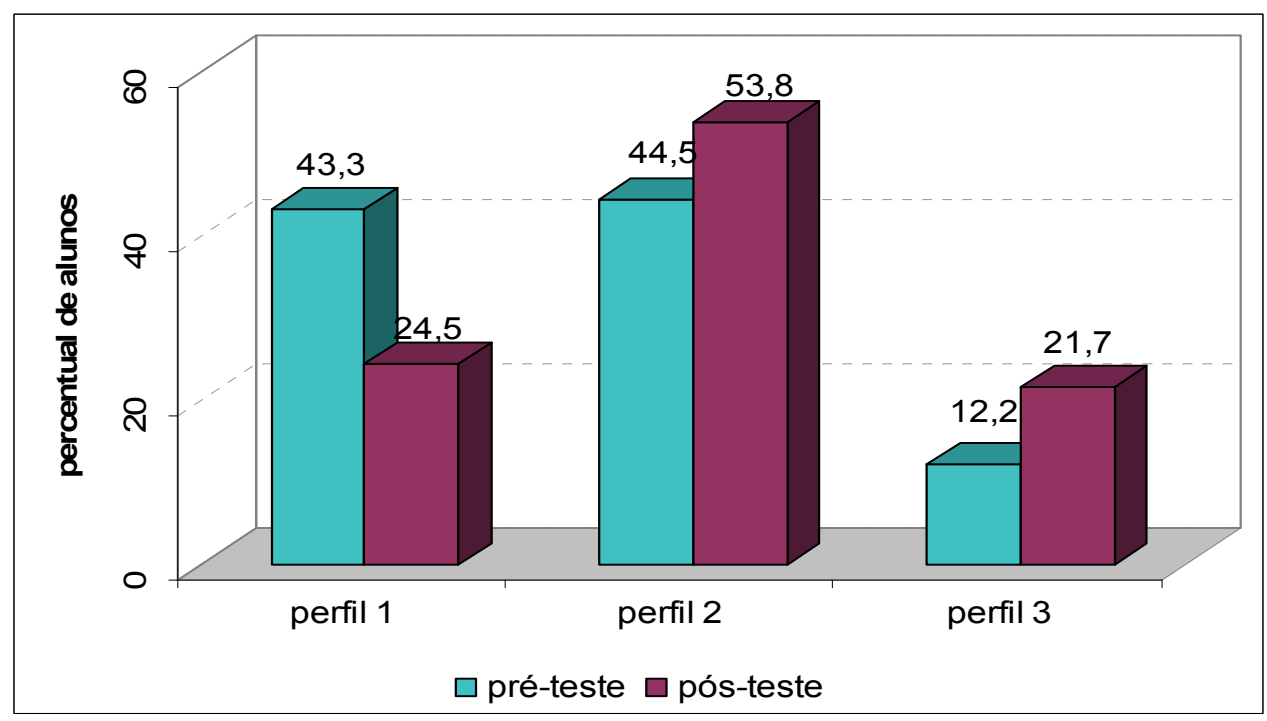

O gráfico 2 revelou crescimento nos perfis 2 e 3, aumento que representou um ganho de $21 \%$ na freqüência do perfil 2, e de $77 \%$ no perfil 3. O perfil 2, ao final do curso, envolvia 609 alunos-professores $(53,8 \%)$ cuja atuação docente era formal e pouco criativa, mesmo revelando a intenção de estabelecer vínculos com os alunos. Eles, agora, buscavam construir um ambiente de aprendizagem adequado e agradável, selecionando atividades que permitissem um trabalho pedagógico rico e 
diversificado. No entanto, os alunos-professores que aí se situaram não conseguiam justificar o emprego das atividades selecionadas, justamente por não terem clareza sobre qual era seu objetivo final e, com isso, elas deixavam de ser devidamente exploradas. Ainda que reconhecendo a valorização do uso de tecnologias na educação matemática, por exemplo, os alunos-professores demonstraram dificuldade em delinear situaçôes em que elas fossem empregadas.

Outros 245 alunos-professores $(21,7 \%)$ enquadraram-se no perfil 3: eram profissionais que procuravam estabelecer vínculos com seus alunos e proporcionar a todos um ambiente de aprendizagem instigante e agradável. Revelavam interesse em promover a autonomia das crianças, em estimular sua participação em aula e em incentivar o exercício da cidadania. Levantavam o conhecimento prévio de seus alunos e contextualizavam o trabalho escolar. Além disso, faziam uso apropriado das tecnologias disponíveis (especialmente, no ensino da matemática) e selecionavam os procedimentos didáticos esperados. Incentivavam a pesquisa e comparavam aquilo que as crianças descobriam à luz das informaçóes inicialmente disponíveis. Em parceria com o grupo-classe, organizavam os resultados obtidos, consolidandoos por meio de registros nos cadernos.

3.1.3 Postura III - Emprego da teoria para orientar a prática docente, nos processos de ensinar, aprender e avaliar

Confrontados os resultados obtidos no pré e pós-teste pelos alunos-professores, no conjunto de simulaçóes que dizia respeito ao emprego da teoria para orientar a prática docente nos processos de ensinar, aprender e avaliar (postura III), observou-se, mais uma vez, um deslocamento da freqüência de alunos nos perfis que envolviam as perspectivas apregoadas no Programa. No início do curso, 647 participantes (57,2\%) apresentaram condutas características do perfil 1: afirmavam considerar em seu trabalho os conhecimentos prévios dos alunos, bem como a importância de estimular sua reflexão; porém, quando intervinham em suas classes, não adotavam essa prática, privilegiando atividades voltadas à formalização dos conteúdos. Não exploravam devidamente o erro, deixando de aproveitá-lo para incentivar a aprendizagem dos alunos. Reconheciam a importância de variar os instrumentos de avaliaçáo, mas davam ênfase a resultados obtidos por meio de procedimentos tradicionais, que dificultam a superação das dificuldades enfrentadas pelos alunos. Parte desse grupo, diante de atividades de resolução de problemas, não conseguiu articular os diferentes níveis de dificuldades de seus alunos às suas respectivas faixas etárias e séries, fornecendo respostas incoerentes. Por último, náo aceitavam quando tinham se equivocado e tenta- 
vam disfarçar esse fato diante da classe. Dentre os participantes do curso, 434 sujeitos $(38,4 \%)$ apresentaram características semelhantes a essas ao final do curso; uma redução de 33\% no tamanho inicial desse grupo. O gráfico 3 apresenta a distribuição dos alunos-professores no início e ao final do Programa, nos perfis analisados.

Gráfico 3 - Porcentuais de alunos-professores encontrados nos diferentes perfis da postura III, ao início e ao final do PEC-Município $2^{\text {a }}$ edição

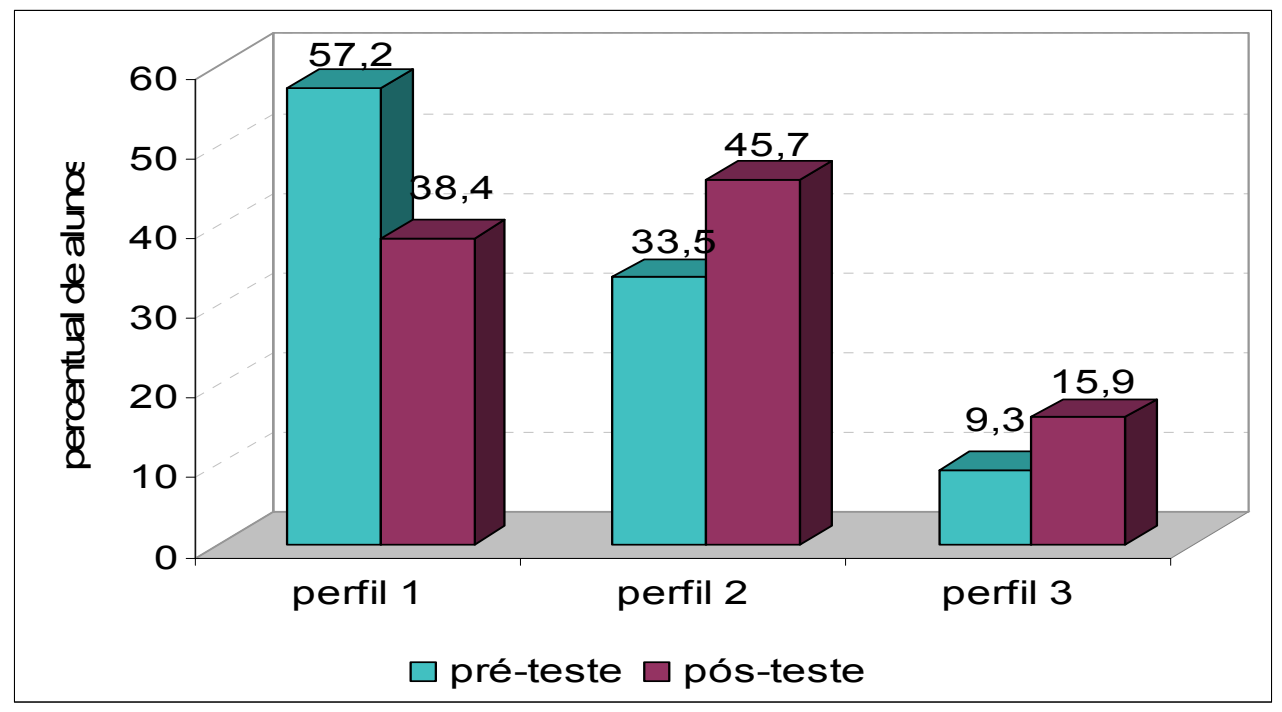

No perfil 2 concentraram-se alunos-professores que consideravam os conhecimentos prévios dos alunos e percebiam a necessidade de estimular a reflexáo e de investigar as razóes dos erros cometidos. No entanto, restringiam-se a essa posição questionadora, sem que efetivamente tentassem ajudar os alunos a encontrar soluçôes eficientes para suas questóes. Articulavam o nível de dificuldade de problemas matemáticos com o nível de desenvolvimento previsto para a faixa etária e série, mas subestimavam as possibilidades cognitivas dos alunos das séries iniciais. Percebiam a possibilidade de tirar proveito dos erros, mas não propunham, no entanto, situaçóes adequadas para que, com base neles, fosse possível impulsionar a aprendizagem.

A maior parte desses profissionais reconhecia formas efetivas de avaliar diferentes dimensóes da experiência escolar, a despeito de se centrarem excessivamente nas atitudes e posturas dos alunos. Adotavam, para auxiliá-los, tanto procedimentos tradicionais como aqueles considerados mais eficientes. Ao empregá-los, no entanto, 
propunham uma seqüência inadequada ou mesmo incoerente de ações, evidenciando que náo os dominavam plenamente. Os resultados do gráfico 3 apontam um aumento do número de alunos-professores, que passou de 33,5\% $(\mathrm{n}=379)$ no pré-teste para 45,7\% (n=517) no pós-teste; um aumento de 36,4\%.

Seguindo a mesma tendência das demais posturas, a maior diferença porcentual entre o pré e o pós-teste foi encontrada no perfil 3. No início do Programa, 105 participantes $(9,3 \%)$ aí se localizavam, ao passo que o pós-teste acusava 180 alunos-professores $(15,9 \%)$, que consideravam os conhecimentos prévios dos alunos, reconheciam os momentos de conflito cognitivo e aproveitavam tais ocasióes para estimular a reflexão sobre a natureza do erro cometido. Articulavam, com pertinência, o nível de dificuldade dos problemas com o nível de desenvolvimento previsto para a faixa etária e série. Assumiam seus equívocos, transformando-os em situação de aprendizagem. No que diz respeito à avaliação, eram capazes de criar e/ ou identificar situaçóes que levavam ao aprimoramento da aprendizagem em várias dimensóes da experiência escolar, bem como ao emprego de práticas de avaliação que maximizavam as possibilidades de sucesso do aluno. Verificou-se, assim, um aumento de $71,4 \%$ de alunos-professores que passaram a atender a um perfil mais condizente com os saberes veiculados pelo PEC-Município $2^{\text {a }}$ edição.

A análise dos dados referentes às três posturas investigadas indicou um impacto positivo do Programa nas posturas dos alunos-professores envolvidos. Observou-se um incremento de mais de $70 \%$ na quantidade de alunos que demonstraram, em suas opçóes diante de situaçóes-problema do cotidiano escolar, perfis de atuaçáo adequados e condizentes com as expectativas do Programa. Esses grupos passaram de cerca de $10 \%$ de freqüência para algo em torno de $20 \%$. Náo desprezando o esforço de trabalho que esse avanço representou, cabe ressaltar, no entanto, que esse índice retratou uma parcela pequena dos alunos-professores do Programa. A maior concentraçáo desses estudantes ao término do curso (entre $43 \%$ e 53\%) foi observada no perfil 2 das três posturas, revelando que, se boa parte do que foi proposto pelo curso foi apropriado pelos professores, restaram ainda fragilidades e inseguranças, em razão de uma atuação docente mais condizente com o preconizado pelo Programa.

\subsection{Influência das características dos alunos sobre as posturas docentes e suas eventuais mudanças}

Após essa primeira leitura e interpretação dos resultados encontrados, fez-se necessário aprofundar as análises, em uma tentativa de esclarecer se, de fato, as alteraçóes de perfis até aqui relatadas eram consistentes e se ocorriam sempre na 
direção esperada. Tratava-se de responder quantos alunos saíram de um perfil menos qualificado para outro mais qualificado e quantos fizeram, eventualmente, o caminho inverso; se existiram alunos que avançaram mais de um nível na mesma categorização proposta para os perfis, ou seja, passaram do perfil 1 para o perfil 3; qual o porcentual de alunos-professores que permaneceu dentro do mesmo perfil no pré e no pós-teste; a que ambientes de aprendizagem pertenciam os estudantes que apresentaram maior alteração de comportamento no sentido esperado entre o início e o fim do curso; identificar onde se encontravam aqueles que permaneceram estagnados ou, inclusive, retrocederam na avaliação.

Para dar seqüência às análises empreendidas, algumas sínteses foram realizadas, com base nas posturas e nos perfis. Para tanto, foi adotado um procedimento que era capaz de expressar, de maneira mais sintética, o desempenho dos participantes. O primeiro passo foi agrupar os alunos-professores que apresentaram, nas três posturas, respostas predominantemente classificadas nos perfis 1, 2 ou 3. Finalmente, aqueles que não responderam de forma consistente nos três e em suas várias posturas foram aglutinados (Tabela 1 ).

Tabela 1 - Porcentual de alunos-professores situados nos quatro grupos de desempenho, nas posturas analisadas

\begin{tabular}{c|c|c|c}
\hline \multirow{2}{*}{ Grupos } & \multirow{2}{*}{ Classificação dos perfis } & \multicolumn{2}{|c}{ Pré-teste } \\
\cline { 3 - 4 } & & $\mathbf{N}$ & $\%$ \\
\hline $\mathbf{1}$ & Inconsistente & 106 & 7,04 \\
\hline $\mathbf{2}$ & Predominantemente 1 & 733 & 48,70 \\
\hline $\mathbf{3}$ & Predominantemente 2 & 566 & 37,61 \\
\hline $\mathbf{4}$ & Predominantemente 3 & 100 & 6,64 \\
\hline Total & & $\mathbf{1 . 5 0 5}$ & $\mathbf{1 0 0 , 0}$ \\
\hline
\end{tabular}

Como pode ser visto na tabela 1 , a maioria dos participantes $(48,70 \%)$ concentrou-se no grupo 2, indicando prevalência do perfil 1, tido como menos adequado. Esse fato se explica, provavelmente, em razão de ser essa uma avaliação inicial. Por outro lado, não se pode deixar de destacar que um porcentual pequeno $(6,64 \%)$ já apresentava, no início do curso, respostas em que o perfil 3, tido como desejável, prevalecia (grupo 4). De igual modo, não foi alta a quantidade de alunos que ofereceram respostas inconsistentes, oscilando entre os três perfis (1, 2 ou 3), nas várias posturas (grupo 1). 
Uma vez configurados, esses grupos foram reagrupados em apenas dois: o Grupo 2 que resultou da fusão dos grupos 1 e 2 (respostas inconsistentes e respostas notadamente no perfil 1), e o Grupo 4 derivado da reuniáo dos grupos 3 e 4 (em que apareciam, em especial, respostas que foram classificadas no perfil $2 \mathrm{e}$, em menor quantidade, no perfil 3). Conseguiu-se, com isso, um grupo que tinha alcançado respostas consideradas mais inadequadas (resultado da reuniáo dos grupos 1 e 2) e, outro, cujas respostas eram tidas como mais adequadas (provenientes da junção dos grupos 3 e 4). Os dados resultantes desses agrupamentos obtidos no pré-teste e no pós-teste aparecem sintetizados no gráfico 4 , a seguir.

Gráfico 4 - Porcentual de alunos-professores situados nos grupos 2 (desempenhos que se afastavam do esperado) e 4 (desempenho que se aproximavam do desejado)

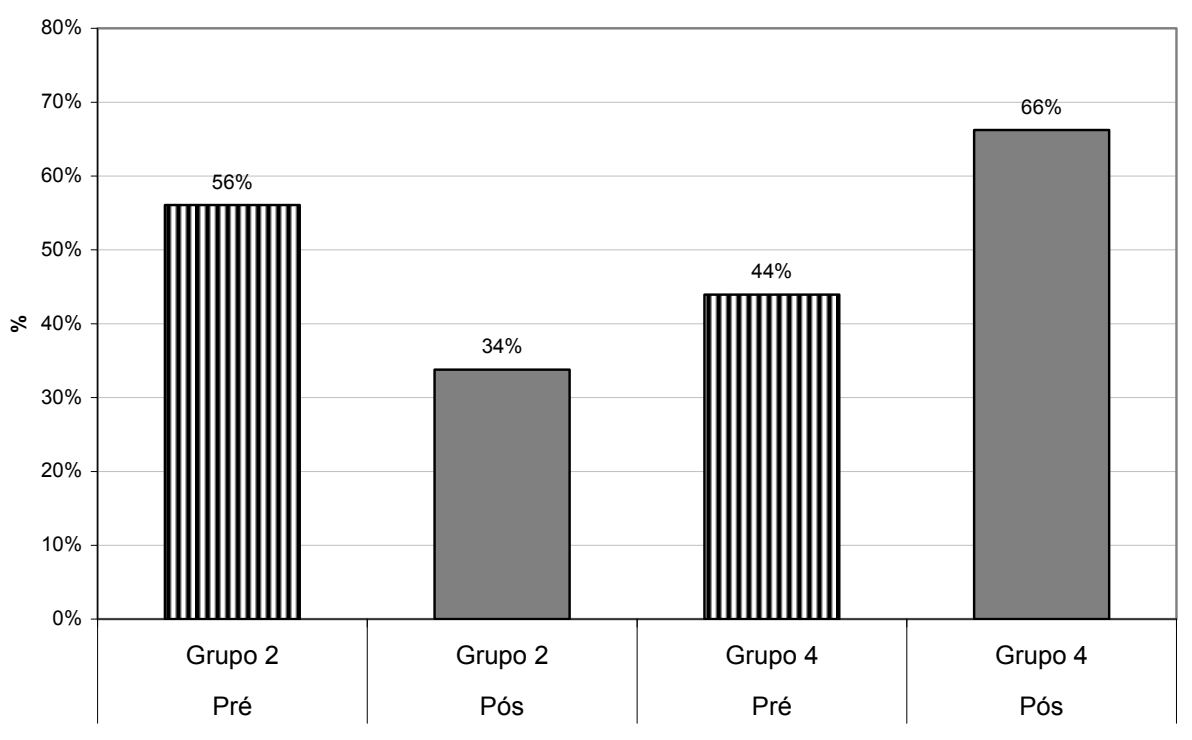

Nota-se, pelos dados reunidos no gráfico 4, que houve, ao final do curso, expressiva mudança no padrão de respostas apresentado pelos alunos-professores. $\mathrm{Na}$ fase inicial, a maioria dos participantes (56\%) concentrava-se no Grupo 2, e 44\% alcançavam os níveis de desempenho mais próximos do esperado (Grupo 4). Essa tendência alterou-se significativamente na avaliação final, momento em que diminuiu o porcentual dos que foram classificados no Grupo 2 que, agora, correspondia a aproximadamente $1 / 3$ do total. Isso permitiu verificar que grande parte dos alunos-professores (66\%) atingiu os níveis de desempenho mais altos (Grupo 4). 


\subsubsection{Diferenças no desempenho dos subgrupos de participantes}

Complementando os estudos sobre desempenho nas posturas docentes, foram aplicados dois outros procedimentos de análise estatística. $\mathrm{O}$ primeiro deles - a análise de "clusters" - procedimento que permite identificar grupos relativamente homogêneos em termos do desempenho - separou, em dois grandes grupos, os resultados obtidos pelo conjunto dos alunos de cada Ambiente de Aprendizagem no pré-teste, os quais ficaram assim constituídos:

Grupo A - reuniu os participantes que realizaram o curso em 12 Ambientes de Aprendizagem e que apresentaram, no pré-teste, um conjunto de perfis mais próximos dos que seriam desejáveis de acordo com o Programa oferecido.

Grupo B - formado pelos participantes reunidos nos demais 14 Ambientes de Aprendizagem que revelaram posturas mais distantes das esperadas no início do curso.

Os resultados desses grupos no conjunto dos perfis das três posturas analisadas (grupo 2 ou grupo 4 de desempenho) aparecem sintetizados na tabela 2, a seguir.

Tabela 2 - Avaliação dos grupos dos Ambientes de Aprendizagem no início e ao final do Programa

\begin{tabular}{|c|c|c|c|c|c|c|}
\hline \multirow{2}{*}{\multicolumn{2}{|c|}{ Avaliados Avaliação }} & \multicolumn{2}{|c|}{ Pré-teste } & \multicolumn{2}{|c|}{ Pós-teste } & \multirow{3}{*}{$\begin{array}{l}\text { Total } \\
426\end{array}$} \\
\hline & & Grupo 2 & Grupo 4 & Grupo 2 & Grupo 4 & \\
\hline \multirow{4}{*}{$\begin{array}{l}\text { Ambientes de } \\
\text { Aprendizagem }\end{array}$} & \multirow{2}{*}{$\begin{array}{l}\text { Grupo A } \\
\text { ("Cluster 1") }\end{array}$} & 178 & 248 & 182 & 244 & \\
\hline & & $42 \%$ & $58 \%$ & $43 \%$ & $57 \%$ & $100 \%$ \\
\hline & \multirow{2}{*}{$\begin{array}{l}\text { Grupo B } \\
\text { ("Cluster 2") }\end{array}$} & 456 & 249 & 200 & 505 & 705 \\
\hline & & $65 \%$ & $35 \%$ & $28 \%$ & $72 \%$ & $100 \%$ \\
\hline \multirow{2}{*}{\multicolumn{2}{|c|}{ Total }} & 634 & 497 & 382 & 749 & 1131 \\
\hline & & $56 \%$ & $44 \%$ & $34 \%$ & $66 \%$ & $100 \%$ \\
\hline
\end{tabular}

Os dados apontaram que no Grupo A (“Cluster 1”) - que reuniu os 12 Ambientes de Aprendizagem com melhor desempenho na etapa inicial da avaliação - praticamente não foram observadas mudanças nos porcentuais de alunos-professores classificados nos dois grupos extremos (Grupo 2: 42\% e 43\% e Grupo 4: 58\% e 57\%, no 
pré e pós-teste, respectivamente) do pré-teste para o pós-teste. No Grupo B (“Cluster 2 "), no entanto, a melhoria foi sensível: diminuiu o porcentual dos alunos-professores classificados no Grupo 2 (65\% para 28\%) e aumentou o porcentual dos que passaram a constituir o Grupo 4 (35\% para 72\%). Tais resultados indicaram que mudanças na postura dos participantes foram mais significativas no Grupo B, que apresentava, no início do Programa, respostas mais distantes do padrão desejado.

3.2.2 Características do perfil dos participantes associadas ao desempenho, no pré e no pós-teste

Para verificar quais eram as características dos participantes que poderiam estar associadas a diferentes perfis, partiu-se dos dois grupos extremos de desempenho e procedeu-se a uma tabulação das informaçóes levantadas por meio do questionário aplicado pela equipe gestora do Programa. Os resultados dessa tabulaçáo permitiram detectar diferenças na distribuição das respostas apresentadas pelos integrantes dos dois grupos e, portanto, selecionar as variáveis que deram origem à composição de sete indicadores: atuação profissional, faixa etária, uso da informática, formação, hábitos culturais e de lazer, motivaçâo para realizar o Programa e práticas pedagógicas. A síntese dos resultados obtidos para cada um desses indicadores é apresentada a seguir.

Atuação profissional: os dados indicaram que mudanças mais significativas no desempenho dos participantes, entre o pré e o pós-teste, foram observadas no grupo dos que lecionavam em apenas uma escola municipal; atuavam como docentes há 15 anos ou mais; trabalhavam na escola há 8 anos ou mais e exerciam sua atividade em uma creche. Nesse grupo, $50,6 \%$ dos participantes passaram da categoria 2 para a categoria 4; 26,3\% mantiveram-se estáveis na categoria 4 e, portanto, a maioria $(76,9 \%)$ atingiu, no pós-teste, níveis de desempenho que se enquadraram nos padróes esperados.

Faixa etária: os resultados apontaram que os participantes com idade igual ou superior a 41 anos foram os que registraram resultados mais positivos na comparação entre o pré e o pós-teste. Nesse grupo, 49,5\% dos participantes passaram da categoria 2 para a categoria $4 ; 27,8 \%$ mantiveram-se estáveis na categoria 4 . Nos pós-teste, o porcentual dos que atingiram o padrão de respostas esperado foi de $77,4 \%$.

Uso da informática: as alterações positivas no desempenho dos participantes, entre o pré e o pós-teste, foram notadas nos dois grupos de participantes, uma vez que os porcentuais relativos aos que atingiram a categoria 4 , no pós-teste, são muito próximos: $67,4 \%$ e $65,8 \%$. Deve-se destacar, no entanto, que o porcentual dos que 
passaram da categoria 2 para a categoria 4 é maior no grupo dos que, ao iniciar o Programa, informaram não ter acesso ao uso de computadores.

Formação: mudanças mais significativas no desempenho dos participantes, entre o pré e o pós-teste, foram verificadas no grupo dos que realizaram um curso do ensino médio regular, supletivo, ou da modalidade programa especial (Magistério).

Hábitos culturais e de lazer: a análise desse indicador permitiu concluir que embora os porcentuais dos que obtiveram no pós-teste desempenhos satisfatórios tenham sido muito próximos (67,4\% para o grupo com escore baixo no indicador e $64,6 \%$ para o grupo com hábitos culturais mais diversificados), no primeiro grupo o porcentual dos que mudam de patamar é mais alto do que o observado no segundo grupo: $44,6 \%$ versus $29,7 \%$.

Motivação para realizar o PEC-Município: notou-se que entre os alunos-professores que não alcançaram desempenho satisfatório no pré-teste, 519 (81,9\%) não apresentaram motivos para participar do curso e $115(18,1 \%)$ apontaram o prestígio das universidades envolvidas e/ou a indicação de colegas como fatores importantes. Para os que iniciaram o Programa apresentando respostas classificadas na "categoria 2" não há diferenças significativas entre o desempenho dos grupos separados pelo indicador. No extremo oposto, ou seja, para os que apresentaram bom desempenho no pré-teste, observa-se que o porcentual de professores que atingem a "categoria 44 " é mais alto no grupo com escore baixo no indicador: $65,0 \%$ contra $58,8 \%$.

Práticas pedagógicas: os dados indicam que embora o desempenho dos dois grupos diferenciados pelo escore no indicador em foco seja muito próximo, há uma tendência apontando melhores resultados para o grupo que informou desenvolver práticas pedagógicas mais adequadas: $69,8 \%$ dos que declararam fazer uso de materiais e/ou de informaçóes a respeito das características da comunidade foram classificados no grupo 4 no pós teste, enquanto $65,2 \%$ dos que informaram náo utilizar ou utilizar menor número de materiais de apoio foram assim classificados.

Com base em cada um desses indicadores, procedeu-se, então, a uma nova tabulação, cujo intento era o de examinar as relaçóes existentes entre as características do perfil dos alunos-professores e seus desempenhos, tanto no pré como no pós-teste.

3.2.3 Influência das características dos participantes nos resultados alcançados nas duas etapas da avaliação

As diferentes características dos participantes, sintetizadas nos sete indicadores mencionados anteriormente, mostraram associar-se às diferenças observadas 
Tabela 3 - Resultados obtidos no pré-teste e no pós-teste, segundo o Ambiente de Aprendizagem

\begin{tabular}{|c|c|c|c|c|}
\hline $\begin{array}{l}\text { Ambientes de } \\
\text { Aprendizagem }\end{array}$ & $\begin{array}{c}\mathrm{N}^{\circ} \mathrm{de} \\
\text { alunos }\end{array}$ & $\begin{array}{c}\text { Média no } \\
\text { Indicador de } \\
\text { Desempenho: } \\
\text { Pré-teste }\end{array}$ & $\begin{array}{c}\text { Média no } \\
\text { Indicador de } \\
\text { Desempenho: } \\
\text { Pós-teste }\end{array}$ & $\begin{array}{c}\text { Ganho médio } \\
\text { entre o Pré- } \\
\text { teste e o Pós- } \\
\text { teste }\end{array}$ \\
\hline 1 & 35 & 5,05 & 4,38 & $-0,67$ \\
\hline 2 & 24 & 5,69 & 4,72 & $-0,97$ \\
\hline 3 & 17 & 5,10 & 5,69 & 0,59 \\
\hline 4 & 29 & 5,63 & 4,83 & $-0,80$ \\
\hline 5 & 33 & 4,44 & 5,25 & 0,81 \\
\hline 6 & 32 & 4,48 & 5,31 & 0,83 \\
\hline 7 & 37 & 3,60 & 5,95 & 2,34 \\
\hline 8 & 91 & 4,62 & 6,15 & 1,54 \\
\hline 9 & 48 & 4,58 & 6,39 & 1,81 \\
\hline 10 & 32 & 5,52 & 5,31 & $-0,21$ \\
\hline 11 & 25 & 4,80 & 4,00 & $-0,80$ \\
\hline 12 & 45 & 6,15 & 4,37 & $-1,78$ \\
\hline 13 & 34 & 4,41 & 6,76 & 2,35 \\
\hline 14 & 58 & 4,25 & 6,44 & 2,18 \\
\hline 15 & 46 & 4,71 & 6,38 & 1,67 \\
\hline 16 & 79 & 4,43 & 6,24 & 1,81 \\
\hline 17 & 46 & 4,28 & 6,16 & 1,88 \\
\hline 18 & 49 & 6,19 & 4,69 & $-1,50$ \\
\hline 19 & 14 & 4,76 & 5,24 & 0,48 \\
\hline 20 & 51 & 4,77 & 6,14 & 1,37 \\
\hline 21 & 60 & 3,94 & 6,78 & 2,83 \\
\hline 22 & 21 & 5,08 & 4,76 & $-0,32$ \\
\hline 23 & 47 & 4,68 & 6,95 & 2,27 \\
\hline 24 & 51 & 4,84 & 6,01 & 1,18 \\
\hline 25 & 83 & 4,38 & 6,43 & 2,05 \\
\hline 26 & 44 & 5,91 & 5,61 & $-0,30$ \\
\hline
\end{tabular}

nos desempenhos obtidos, tanto no pré-teste como no pós-teste. No entanto, para que fosse possível levar em consideração a interação existente entre esse conjunto de variáveis, foi necessário adotar um procedimento que permitisse identificar náo só a influência isolada de cada uma delas como, também, o processo de interação entre elas. Para tanto, dois outros procedimentos de análise foram adotados. O primeiro resultou na criação de um indicador de desempenho que 
seguiu, em sua construção, a mesma lógica que fundamentou a elaboração do Índice de Desenvolvimento da Educaçáo do Estado de São Paulo - Idesp³. Esse indicador, que variava de 0 (menor valor) a 10 (maior valor), foi calculado tanto para os resultados obtidos no pré como no pós-teste, em todos os Ambientes de Aprendizagem. Em seguida, foi calculada a diferença entre o desempenho no pré-teste e no pós-teste, obtendo-se um escore que expressou a diferença ("ganhos") entre o comportamento de entrada e o de saída dos participantes. Esse escore final representa, em certa medida, o impacto do Programa no que concerne à avaliação das posturas docentes.

O segundo procedimento consistiu na aplicação da técnica AID (Automatic Interaction Detection) para realizar uma análise exploratória e hierárquica dos dados alcançados por meio dos indicadores de perfil e do indicador relativo às mudanças nas posturas investigadas entre o pré e o pós-teste.

Essa análise fez com que o conjunto total dos participantes fosse separado, inicialmente, em dois grandes subgrupos. A partir desse primeiro nível de segmentaçáo, os procedimentos de análise criaram subgrupos cada vez menores, sempre derivados dos que foram selecionados nos níveis superiores da hierarquia. $\mathrm{O}$ processo de subdivisão em grupos continuou até não se encontrar nenhuma outra variável capaz de influenciar os resultados. No processo de subdivisão, foi considerado, ainda, o tamanho dos grupos resultantes. Os subgrupos identificados eram mutuamente exclusivos e completos, o que significava que não havia sobreposição entre eles, e que cada indivíduo era computado uma única vez e em um único grupo.

3.2.4 Resultados relativos aos avanços, ou retrocessos, na síntese das posturas investigadas

Os resultados da técnica AID, apresentados no diagrama 1, mostram, dentre os indicadores construídos, os que foram capazes de influenciar os resultados obtidos nas simulaçóes. Por exemplo, a média no indicador "ganhos" de desempenho, para o conjunto total de participantes incluídos no estudo (nó $0 ; \mathrm{N}=1.131$ ), foi igual a

\footnotetext{
${ }^{3}$ Para maiores informações sobre o Idesp, consulte-se o documento "Definição de metas de desempenho para as escolas estaduais paulistas de ensino básico". Menezes Filho, Naércio; Soares, José Francisco e Terra, Rafael, 2008. Os procedimentos utilizados na criação do indicador utilizado nesta avaliação de posturas docentes estão disponíveis no Relatório Técnico Final: Avaliação de posturas docentes. PEC-Município 2a edição. Fundação Carlos Chagas.
} 
1,06. Isso significou que, ao comparar o mesmo grupo antes e após a participação no Programa, uma sensível melhoria foi encontrada (mais de um ponto, em média, entre o pré e o pós-teste) em termos do conjunto das posturas docentes. O desvio padrão registrado foi, nesse caso, igual a 1,30, indicando a variabilidade existente no grupo de alunos-professores.

O conjunto que apresentou maior crescimento, em termos de desempenho na síntese dos perfis estudados, do pré para o pós-teste, foi o quinto (nó 5), formado por 293 alunos-professores (25,9\% do total) vinculados a Ambientes de Aprendizagem do grupo B (que apresentaram resultados inferiores no pré-teste) e coordenados pelo pólo 1. Nesse grupo, a média dos "ganhos de desempenho" foi igual a 2,05. Resultados também positivamente expressivos foram alcançados por 271 estudantes ( $24 \%$ do total) do nó 17 que, apresentando as mesmas características anteriores, se diferenciavam por possuírem menor formação (estudos que iam até o Ensino Médio regular ou supletivo) e por náo terem tido oportunidade de realizar cursos de formação continuada. A média (em termos de ganhos) desse agrupamento foi a segunda melhor de todas: 1,83 .

Os dados sintetizados no diagrama 1 indicam que resultados menos animadores foram encontrados no décimo terceiro conjunto (nó 13), que reuniu 47 alunos-professores (4,2\% do total) cujos Ambientes de Aprendizagem figuravam no grupo A e estavam sob a coordenação do pólo 1. A atuação profissional desses alunos-professores concentrava-se, predominantemente, entre os que lecionavam em apenas uma escola municipal, atuavam como docentes há 15 anos ou mais e trabalhavam na mesma unidade escolar há pelo menos 8 anos, exercendo o magistério na condição de professores para crianças matriculadas em creches. Esses alunos-professores pertenciam ao grupo mais jovem, situado, majoritariamente, na faixa etária até 40 anos. A média do indicador "ganhos de desempenho" foi negativa $(-0,15)$, sinalizando um nível de realização inferior ao que fora obtido no pré-teste. Deve-se destacar, no entanto, que o desvio padrão $(1,23)$ indica que se trata de um grupo de composiçáo pouco uniforme em termos do desempenho observado nas situaçóes-problema que lhe foram apresentadas. 


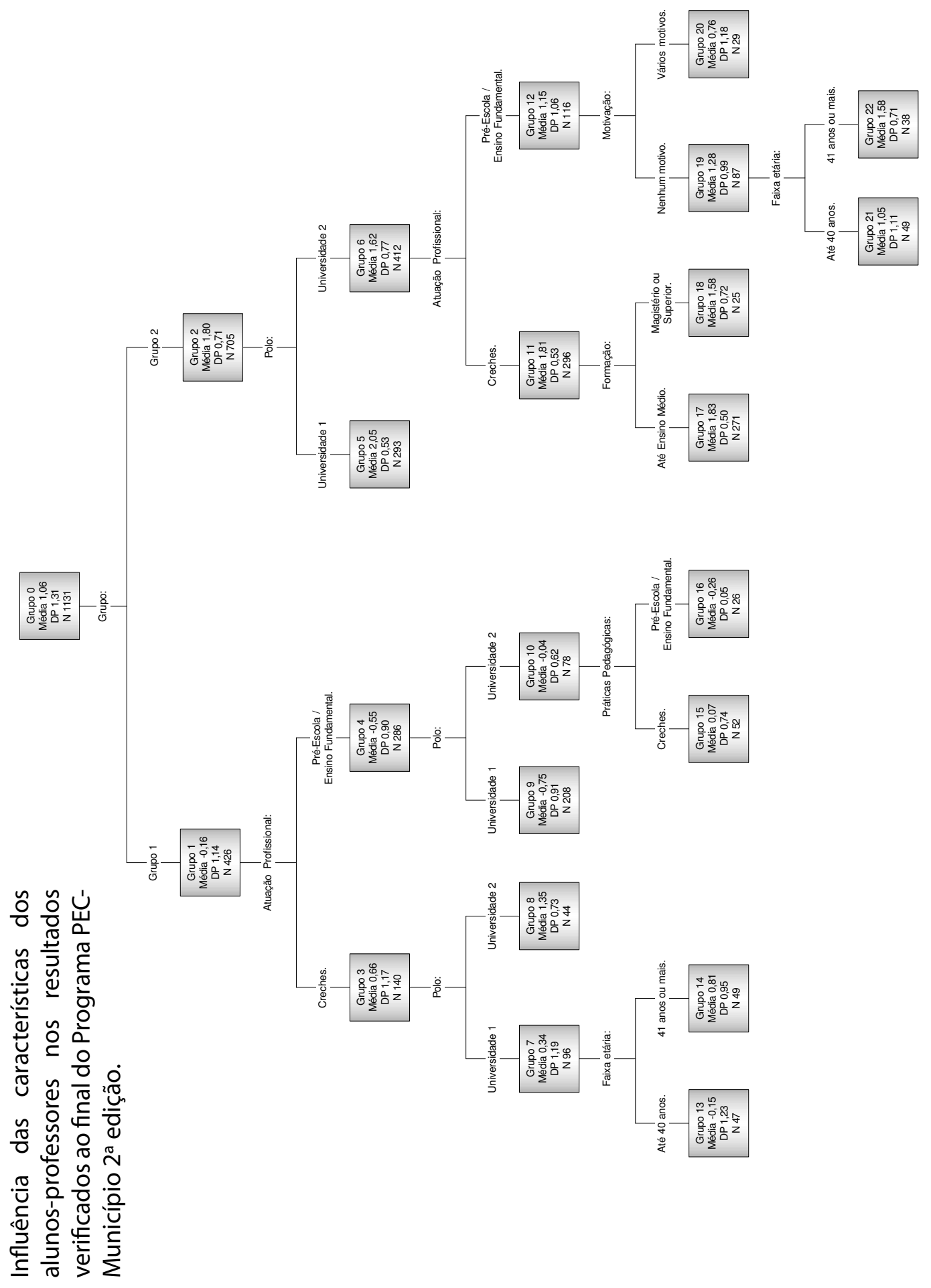




\section{CONSIDERAÇÕES FINAIS}

Os resultados apresentados neste artigo apontam que os alunos-professores obtiveram, do início para o final do curso, avanços em relação às posturas docentes estudadas: a postura I, que investigava o domínio e o planejamento de conteúdos básicos das áreas de conhecimento tratadas no Programa; a postura II, que buscava aferir o reconhecimento e emprego adequado de recursos e tecnologias disponíveis no processo de ensino-aprendizagem; e a postura III, na qual se averiguava o emprego da teoria para orientar a prática docente, nos processos de ensinar, aprender e avaliar. No pré-teste verificou-se que a maior freqüência de alunos-professores encontrava-se sempre no perfil 1 de cada uma das posturas (em torno de 50\%), indicando predomínio daquelas consideradas menos adequadas pelos idealizadores do Programa.

A situação inicial retratou profissionais com concepçóes menos atualizadas de educação, o que os levava a ter uma atuação mais tradicional como, por exemplo, valorizar apenas a aquisição do código da escrita, não se preocupar com os vínculos em sala de aula, resistir ao emprego de novas tecnologias ou privilegiar apenas atividades voltadas à formalização de conteúdos. $\mathrm{O}$ perfil 1 das três posturas reunia, também, profissionais que apresentaram uma atuação "inconsistente", que indicava dificuldade em reconhecer, organizar ou articular procedimentos pedagógicos a recursos didáticos e justificar coerentemente as práticas adotadas.

Os dados do pós-teste apontaram uma maciça migração para o perfil 2 em todas as posturas, de modo que o perfil 1 diminuiu sensivelmente após o curso. Essa mudança pode ser entendida como decorrente do fato de os alunos-professores terem incorporado novos conhecimentos específicos a respeito do processo educacional, os quais começaram a interferir nas posturas antes anunciadas. Pode-se notar, por exemplo, o fato de passarem a considerar os conhecimentos prévios dos alunos e a escolher seqüências didáticas motivadoras, o que o Programa considerava relevante. No entanto, a mudança observada não se fez acompanhar de um entendimento claro acerca das razóes pelas quais essas seqüências eram mais interessantes para a aprendizagem dos alunos. Sem as compreender, não conseguiram justificá-las de maneira consistente.

Pode-se dizer, assim, que a atuação desses alunos-professores permanecia ainda formal, pouco criativa e pouco afetiva, muito embora já se revelasse aí a intenção de estabelecer vínculos mais próximos com os alunos. Os participantes começaram também a reconhecer a importância do uso de tecnologias na educação matemática, encontrando, no entanto, dificuldades em delinear situaçóes em que fossem adequadamente empregadas. A maior parte desses profissionais passou a reconhecer formas efetivas de avaliar diferentes dimensóes da experiência escolar, mas, nessa 
tentativa de valorizar o processo do aluno, acabou por desconsiderar a importância da apropriação dos conteúdos trabalhados.

Essas mudanças, por significativas que tenham sido, comportavam, ainda, múltiplas possibilidades de serem aprimoradas, de modo que, muito provavelmente, o tempo necessário para que maiores avanços fossem observados não coincidiu com a duração do curso. Outro fator a ser considerado foi o acúmulo de informaçóes por parte de alunos-professores que apresentavam muitas defasagens, algo que requereria mais tempo e uma maior sistematização para serem efetivamente incorporadas. Não se pode desconsiderar, também, outros aspectos que poderiam ter dificultado ou favorecido o aproveitamento do curso e que não foram aqui investigados, como, por exemplo, a atuação da tutora, o cansaço ao conciliar estudo e trabalho, o pouco tempo para realizar leituras ou, mesmo, a pouca familiaridade com o texto científico ou literário.

A análise final desta avaliação contemplou, simultaneamente, a síntese dos resultados nas posturas e as características dos sujeitos. O estudo mostrou que o curso teve um impacto positivo nesse grupo de alunos-professores: se $25 \%$ do grupo total apresentou desempenho inferior, os progressos alcançados pelos $75 \%$ que avançaram durante o curso foram, em média, bastante significativos. Os principais fatores que interferiram nos resultados observados foram o ponto de partida, a atuaçáo profissional e o pólo (universidade) a que os participantes estavam vinculados. Por outro lado, náo se pode deixar de ressaltar, ao final deste artigo, que o grupo que se mostrou inicialmente mais despreparado e com perfis docentes bem distantes dos pretendidos pelo Programa foi justamente o que apresentou maiores ganhos. Como já mencionado, são os alunos-professores que:

- pertenciam ao Grupo 2;

- eram mais velhos;

- não utilizavam com freqüência o computador;

- náo recebiam orientaçóes e/ou capacitaçóes que lhes permitissem realizar o planejamento de suas atividades, nem utilizar materiais de apoio e informaçóes sobre a realidade de seu contexto escolar;

- com formação escolar relativa a um curso de Ensino Médio, sem correspondência com os cursos de preparação para o magistério;

- náo tiveram oportunidade de realizar cursos de aperfeiçoamento;

- trabalhavam predominantemente em creches;

- acumulavam mais de 15 anos de experiência como professores (ainda que não habilitados formalmente para a função); e/ou

- atuavam na mesma unidade escolar há 8 anos ou mais. 
Essa alteração substancial de cenário deveu-se, em parte, ao patamar de entrada desses participantes, que enfrentavam em suas rotinas de trabalho condiçóes efetivamente menos favoráveis do que os demais. Assim, ao que tudo indica, mudanças de posturas parecem ocorrer com maior intensidade em grupos mais frágeis em termos de conhecimento e de domínio de técnicas de ensino apropriadas a alunos da Educação Infantil e do primeiro segmento do Ensino Fundamental. Isso demonstrou que, especialmente entre tais professores, é preciso estar atento à direção que as posturas tomam em seu cotidiano. Nesse sentido, fica a recomendaçáo para que programas de capacitaçáo docente em serviço acompanhem os grupos mais fragilizados com maior desvelo, atendendo ao princípio da eqüidade.

\section{REFERÊNCIAS BIBLIOGRÁFICAS}

COLL, C. et al. Os Conteúdos na reforma: ensino fundamental. Cadernos de Pesquisa, v. 37, n. e aprendizagem de conceitos, procedimentos e atitudes. Rio Grande do Sul: Artmed, 1992.

DAVIS, C. et al. Posturas docentes e formação universitária de professores do ensino 130, p. 227- 245, jan./abr. 2007. FUNDAÇÃO CARLOS CHAGAS. Avaliação de Posturas Docentes: PEC-Município/2a edição, julho, 2008. (Relatório Técnico Final)

Recebido em: maio 2008

Aprovado para publicação em: julho 2008

Claudia Davis é pesquisadora da Fundação Carlos Chagas e leciona no programa de pós-graduação em Psicologia da Educação, da Pontifícia Universidade Católica de São Paulo; Yara Lúcia Esposito é pesquisadora da Fundação Carlos Chagas; Marina Muniz Rossa Nunes é pesquisadora da Fundação Carlos Chagas e orientadora educacional do Colégio Santa Cruz; Cesar Augusto Amaral Nunes dirige a OORT Tecnologia, é orientador no programa Interunidades de Ensino de Ciências da Universidade de São Paulo e coordena projetos na Fundação de Apoio à Faculdade de Educação. 